\title{
DUCCIO BONAVIA BERBER
}

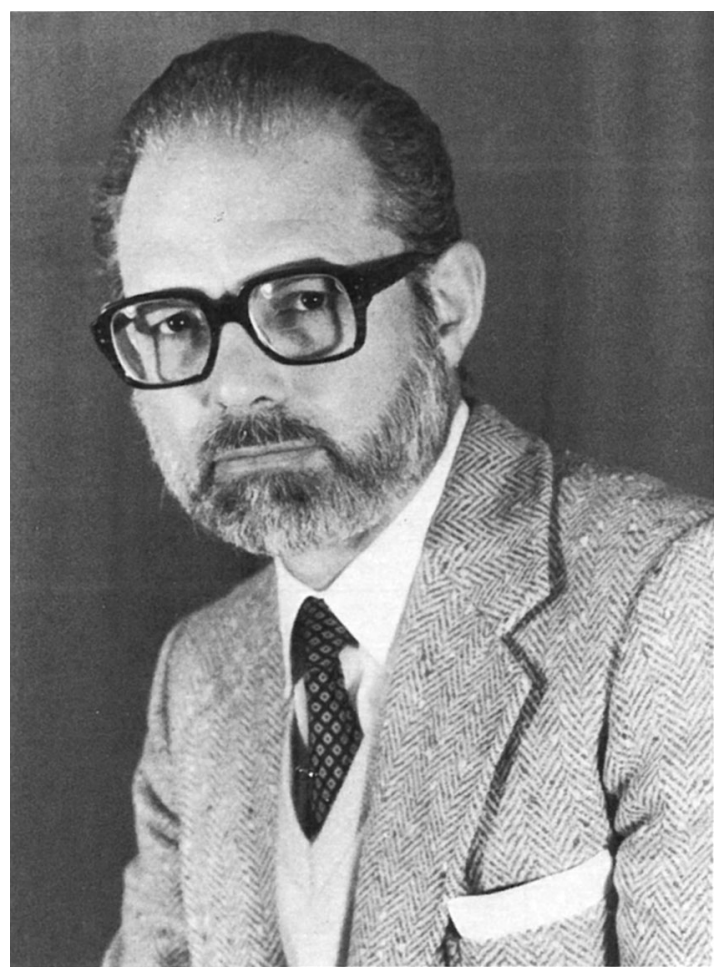

Figura 1. Duccio Bonavia Berber (1935-2012). En Mural Painting in Ancient Perú, por Duccio Bonavia, 1985.

El primer número de la revista científica Devenir salió a la luz en junio de 2014, casi dos años después del fallecimiento del doctor Bonavia. Dada la trascendencia de su labor intelectual y su obra, ambas vinculadas al patrimonio cultural, el Consejo Editorial consideró oportuno rendirle homenaje difundiendo su producción entre las nuevas generaciones.

Duccio Bonavia nació el 27 de marzo de 1935 en Spalato (Dalmacia), en territorios de la antigua República Federal de Yugoslavia, país al que su familia, de origen italiano, había emigrado. Spalato es sin duda una de las ciudades históricas más importantes del litoral del mar Adriático, que atesora en su centro histórico el palacio del emperador romano Dioclesiano, construido en el siglo IV de nuestra era. Por sus vínculos familiares cursó sus estudios secundarios y el Liceo Científico en Italia, en Bassano del Grappa y Treviso (1945-1948). En ese último año su familia decidió emigrar nuevamente, esta vez al Perú, apremiadas por las duras condiciones de vida en la Europa del período que siguió a la Segunda Guerra Mundial.

Ya establecido en Lima siguió la profesión de arquitecto. Ingresó primero a la Escuela Nacional de Ingenieros, donde cursó estudios entre 1952 y 1954. Luego, decidió cambiar su orientación vocacional y seguir la carrera de Etnología en la Universidad Nacional de San Marcos (UNMSM), donde estudió entre 1956 y 1960, y se especializó en Arqueología.

Después de obtener el bachillerato, siguió los cursos de especialidad para obtener el doctorado, grado que consiguió con una importante investigación sobre los yacimientos arqueológicos del valle de Lurín. En esos mismos años, Bonavia se desempeñó como jefe del equipo técnico de historiadores y arqueólogos de la Junta Deliberante Metropolitana de Monumentos Históricos y Artísticos, y Lugares Arqueológicos de Lima. Dicho equipo estableció el perímetro de cada yacimiento prehispánico conocido en la ciudad. 
devenir Vol.6, N¹1, ENERO - JUNIO 2019, PP. 5-6 - IN MEMORIAM | ISSN 2312-7562 | E-ISSN 2616-4949

UnIVERSIDAD NACIONAL DE INGENIERÍA, LIMA

doi: https://doi.org/10.21754/devenir.v6i11.630

Su inquietud por estudiar y entender otros contextos culturales lo llevó a ser profesor de Arqueología en la Universidad Nacional San Cristóbal de Huamanga, en Ayacucho, entre 1963 y 1964. Por su voluntad de ampliar horizontes, aceptó en 1964 ser jefe del Departamento de Exploraciones del Museo Nacional de Antropología y Arqueología de Lima, a la par que se dedicaba a la enseñanza de Pre-Historia General en la UNMSM. Su proverbial laboriosidad lo condujo a desempeñar también el cargo de jefe de investigaciones en la Casa de la Cultura del Perú. En 1968 publicó su libro Las Ruinas del Abiseo, donde analiza de primera mano el conjunto el Gran Pajatén.

Fue un investigador apasionado que llegó a alcanzar renombre internacional gracias a su entrega y capacitación personal. Recibió becas del Museo Botánico de Harvard; del Ministerio de Relaciones Exteriores de Francia, para la Universidad de Bordeaux; del Royal Ontario Museum de Canadá; de la Fundación Ford; y de la John Simon Guggenheim Foundation de Nueva York (León, 2012). Se trataba de una persona reflexiva y perfeccionista, muy exigente consigo misma, apegada a claros preceptos éticos. Esas peculiaridades le otorgaban una imagen muy severa.

Su labor más estable y productiva se desarrolló en el medio universitario e inició alrededor de 1978, cuando pasó a formar parte del Departamento de Biología de la Universidad Peruana Cayetano Heredia (UPCH), donde llegó a ser profesor principal. Luego fue reconocido por la Universidad de Bonn, Alemania, que lo eligió como profesor visitante entre 1981 y 1984. Fue además investigador asociado del Departamento de Arqueología del Nuevo Mundo del Museo de Ontario, Canadá.

Desde los años 70 sus investigaciones estuvieron encaminadas a conocer el proceso de domesticación del maíz andino, mediante excavaciones arqueológicas en la costa central. Contó con subvenciones de universidades del exterior y colaboradores científicos especializados en genética, paleobotánica, ecología cultural y zooarqueología. Como resultado de estas investigaciones, fue autor y coautor de 14 libros y más de un centenar de artículos científicos que se publicaron en revistas especializadas. Una de sus obras más destacadas, escrita junto con un equipo de investigadores, fue Pre-Cerámico Peruano: Los Gavilanes, Mar, Desierto y Oasis en la Historia del Hombre, libro auspiciado por la Corporación Financiera de Desarrollo y el Instituto Arqueológico Alemán, en el cual sintetiza sus estudios sobre la época Pre-Cerámica en Huarmey y analiza las primeras evidencias de maíz, de 5,000 años de antigüedad.

Interesa destacar su producción vinculada con la historia del arte peruano. En 1974 publicó el libro Ricchata Quelccani: Pinturas Murales Prehispánicas, en el cual, desde la investigación arqueológica, analizó sistemática e interdisciplinariamente la extraordinaria producción pictórica mural de las culturas de la costa peruana. Este libro, ampliado, y con nuevas referencias e ilustraciones, fue publicado en inglés por la Universidad de Indiana, en 1985, bajo el título Mural Painting in Ancient Peru.

Fue precisamente nuestro mutuo interés por la pintura mural lo que permitió que la amistad surgiese. Yo lo había conocido en la década del 70, cuando fui director del proyecto especial del Instituto Nacional de Cultura y la UNESCO para la salvaguarda y restauración de monumentos en el eje Cusco-Puno, pero fue a raíz de la publicación de mi ponencia Mural Painting on Adobe Walls during Peruvian Colonial Times. Its Restoration and Conservation, presentada en un congreso en Bologna, Italia, en 1986, que me escribió una extensa carta, muy a su estilo, alentándome a seguir investigando sobre el tema y haciéndome recomendaciones sobre el rigor que debería guardar. En un posterior libro, Pintura Mural en el Sur Andino', indirectamente trasmití esas recomendaciones metodológicas.

Después de 34 años dedicados a la docencia en la UPCH y a una intensa carrera de investigador, Duccio Bonavia falleció a los 77 años en agosto de 2012. Además de su obra y su ejemplo, nos ha legado una clara muestra de lo que se puede lograr con empeño y pasión por lo que se hace.

\section{Roberto Samanez Argumedo}

\section{Referencias}

León, E. (2012). Duccio Bonavia Berber (1935-2012). Boletín del Instituto Francés de Estudios Andinos, 41 (2), 321.

1. Flores. Kuon, Samanez. (1993). Pintura Mural en el Sur Andino (Vol. Colección Arte y Tesoros del Perú). Lima: Banco de Crédito del Perú. 